Rev. Elet. em Gestão, Educação e Tecnologia Ambiental (e-ISSN: 2236-1170)

\title{
ANÁLISE ECONÔMICA DA CITRICULTURA DE ROSÁRIO DO SUL/RS: UM ENFOQUE SOBRE A ADOÇÃO DE PROGRAMAS DE CERTIFICAÇÃO SOCIOAMBIENTAL
}

\section{ECONOMIC ANALYSIS OF CITRUS ROSARIO DO SUL/RS: A FOCUS ON THE ADOPTION OF ENVIRONMENTAL CERTIFICATION PROGRAMS}

\author{
Sabrina Cantarelli Almeida', Andréa Cristina Dörr², Aline Zulian, Katia Laura Sidali ${ }^{4}$ \\ ${ }^{1}$ UFSM - Aluna de mestrado do Programa de Pós-graduação em Economia \& Desenvolvimento. Email: binalmeida@ig.com.br \\ ${ }^{2}$ UFSM - Professora Adjunta do Departamento de Ciências Econômicas, Professora Permanente junto ao Programa de Pós- \\ graduação em Extensão Rural e do Programa de Pós-Graduação em Economia \& Desenvolvimento (UFSM). Email: \\ andreadoerr@yahoo.com.br \\ ${ }^{3}$ UFSM - Aluna de mestrado do Programa de Pós-graduação em Economia \& Desenvolvimento. Email: alinezulian@hotmail.com \\ ${ }^{4}$ Georg August University Göttingen, Department of Agricultural Economics, Chair of Food Marketing, Germany. E_mail: Katia- \\ Laura.Sidali @agr.uni-goettingen.de
}

http://dx.doi.org/10.5902/223611708803

\section{RESUMO}

O setor frutícola é um dos mais importantes segmentos do agronegócio do Brasil. Além da sua elevada rentabilidade e expressiva utilização de mão-de-obra, a fruticultura destaca-se como uma importante alternativa para o aumento das exportações brasileiras de produtos agrícolas. As novas exigências do mercado refletem na adoção de selos de certificação que comprovam a qualidade e sanidade do produto, o consumidor tem a garantia de um alimento seguro, cuja produção respeita o meio ambiente e o trabalhador. No Rio Grande do Sul, a cultura começou a ser implantada a partir do ano de 2000 quando diversos municípios da região receberam recursos do governo federal, sobretudo, Rosário do Sul, através do Programa de Fruticultura da Metade Sul, sendo uma das beneficiárias a empresa Citrusul. Este artigo tem como objetivo analisar as características de produção e comercialização da empresa, além de identificar os possíveis benefícios de uma futura adoção de programas de certificações socioambientais no setor de citros do município. O estudo foi arquitetado a partir de uma revisão bibliográfica e através de entrevistas para obter informações primárias sobre o assunto. O trabalho mostrou que adoção de selos de certificação traria a oportunidade de acesso a mercados mais nobres e exigentes, uma vez que a empresa já trabalha para ter frutas de excelente qualidade. No entanto, devido ao volume de sua produção atual, acredita-se que os altos custos para seu registro não trazem retorno financeiro necessário para tal investimento.

Palavras-chave: certificação socioambiental, fruticultura, mercado externo

\begin{abstract}
The fruit sector is one of the most important segments of agribusiness in Brazil. In addition to its high profitability and expressive use of hand labor, the fruit stands out as an important alternative to the increase in Brazilian exports of agricultural products. The new market demands reflect the adoption of certification seals that prove the quality and healthiness of the product, the consumer is assured of a safe food whose production respects the environment and the worker. In Rio Grande do Sul, the culture began to be implemented from the year $\mathbf{2 0 0 0}$ when several municipalities in the region received funds from the federal government, especially the Rosary South, through the Program for Fruit of the southern half being a beneficiary of the company Citrusul. This article aims to analyze the characteristics of production and marketing of the company, in addition to identifying the possible benefits of a future adoption of environmental certification programs in the citrus industry in the municipality. This article builds on the literature review and as a way to obtain the information necessary to construct this study, we sought through interviews and case study. The study showed that adoption of certification seals would bring the opportunity to access markets more noble and demanding, since the company is already working to have fruit of excellent quality. However, due to the volume of its current production, it is believed that the high costs for registration need not bring a financial return for such an investment.
\end{abstract}

Keywords: socio-environmental certification, fruit chain, foreign market 


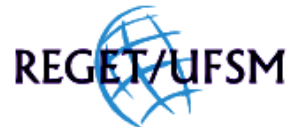

ALMEIDA et all , v(11), no 11, p. 2427-2436, JUN, 2013.

Rev. Elet. em Gestão, Educação e Tecnologia Ambiental (e-ISSN: 2236-1170)

\section{INTRODUÇÃO}

Em um mundo onde cada vez mais o alimento se transforma em um produto industrializado, a procura por alimentos que sejam mais naturais e não prejudiciais à saúde é um fato que começa a estar presente na vida das pessoas. Nessa busca, as frutas podem se tornar grandes aliadas para a manutenção da saúde, pois possuem um grande valor nutricional, com vitaminas, sais minerais, antioxidantes, açúcares naturais, além de várias outras substâncias que auxiliam na prevenção e no combate de doenças (CARVALHO \& MIRANDA, 2009).

O Brasil está entre os principais produtores mundiais de frutas com 42,6 milhões de toneladas produzidas em 2,2 milhões de hectares distribuídos por todo o país. O país apresenta a peculiaridade de produzir frutas tropicais, subtropicais e temperadas em decorrência da extensão territorial, posição geográfica, condições climáticas e de solo, temperaturas entre $21^{\circ} \mathrm{C}$ e $32^{\circ} \mathrm{C}$ e amplitudes térmicas diárias superiores a $10^{\circ} \mathrm{C}$ na época da maturação dos frutos. As exportações de frutas frescas e processadas representam 31\% do total produzido, sendo vendidas para diversas partes do mundo, principalmente à União Europeia, onde seu consumo gira em torno de 70\% (BRAZILIAN FRUIT, 2012).

Segundo dados fornecidos pelo IBGE (2012), no ano de 2010 o agronegócio de citros brasileiro - laranja, lima, limão e tangerina - movimentou cerca de US\$ 4 bilhões de dólares, empregando 5,6 milhões de pessoas, correspondendo a 34\% da mão-de-obra agrícola. No mesmo ano, foram produzidos em torno de 18 milhões de toneladas de laranja, um milhão de toneladas de tangerina e um milhão de toneladas de limas e limões.

Os citros encontram-se entre as frutas mais consumidas pelos brasileiros, sendo cultivados em praticamente todos os estados. Com uma população estimada em 250 milhões de plantas, distribuídas em uma área de 940 mil hectares, são produzidas 20,5 milhões de toneladas de fruta por ano (AGRIANUAL, 2009).

O estado do Rio Grande do Sul é o quinto maior produtor nacional de citros, com produção anual estimada em mais de 545 mil toneladas, realizada em 42 mil hectares, o que gera uma receita direta de $\mathrm{R} \$ 390$ milhões de reais. Embora essa produção seja pequena quando comparada ao estado de São Paulo, ela é maior que a de muitos países e representa a principal atividade econômica de dezenas de municípios (IBGE, 2012).

Em 2011, o estado do Rio Grande do Sul exportou para a União Europeia aproximadamente US\$ 1.700 milhão de dólares de laranjas frescas e secas e US\$ 120 mil dólares de tangerinas frescas e secas (MDIC, 2012).

Dentre as regiões que apresentam as características climáticas necessárias para a produção frutícola, provavelmente, a maior seja a da Fronteira Oeste do RS, onde existem centenas de milhares de hectares disponíveis para a citricultura de mesa. Nessa região, o preço da terra é baixo quando comparado ao dos pólos tradicionais de fruticultura existentes no país, há disponibilidade de mão-de-obra qualificada, de razoável infra-estrutura de transporte terrestre e portuário, de packing-houses públicos e privados refrigerados para o armazenamento das frutas e de financiamentos governamentais para o fomento da produção (OLIVEIRA et al., 2010). 


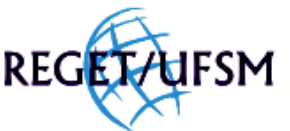

ALMEIDA et all , v(11), no 11, p. 2427-2436, JUN, 2013.

Rev. Elet. em Gestão, Educação e Tecnologia Ambiental (e-ISSN: 2236-1170)

Em razão da excelente qualidade dos frutos produzidos nessa região do estado e dos ótimos preços obtidos pelos produtores, em média, três vezes maiores do que os obtidos com os frutos das cultivares tradicionais de citros, investidores estrangeiros, como uruguaios e espanhóis, e empresários industriais de outras regiões do estado e do país, estão formando pomares na região, cuja economia deve se transformar nos próximos anos, com geração de empregos, renda, fixação do homem no campo e, consequentemente, desenvolvimento rural (OLIVEIRA et al., 2010).

Entre os municípios do estado, Rosário do Sul vem se destacando pela diversificação produtiva e pelo desenvolvimento no setor frutícola, através da produção de laranjas, tangerinas, limões e pêssegos. Atualmente, o município busca, através da fruticultura, maior desenvolvimento sócio-econômico e melhoria da qualidade de vida das famílias. Estima-se que novos investimentos possibilitarão o fortalecimento do setor no município, gerando mais empregos e renda.

Assim, esta pesquisa tem como objetivo analisar as características de produção e comercialização da Citrusul, além de identificar os possíveis benefícios de uma futura adoção de programas de certificações socioambientais no setor de citros do município de Rosário do Sul/RS. Dessa forma, pretende-se analisar questões como: qualidade e segurança das frutas e, também, as exigência para o acesso à exportação.

\section{METODOLOGIA}

Segundo Lakatos \& Marconi (2000, p. 44), "não há ciência sem o emprego de métodos científicos". O estudo deve seguir regras que são importantes na coleta das informações que serão analisadas. Cervo \& Bervian (1996, p. 8) acreditam que "a ciência é entendida como uma busca constante de explicações e soluções, de revisão e reavaliação de seus resultados e tem a consciência clara de sua falibilidade e de seus limites".

Este artigo se constrói a partir de revisão bibliográfica e sua proposta é a de verificar os possíveis benefícios que poderão ser gerados a partir da adoção das normas e procedimentos da certificação socioambiental para o segmento citrícola do município de Rosário do Sul, RS. Como forma de se obter as informações necessárias à construção deste estudo, buscou-se, através de entrevistas e estudo de caso, informações relevantes referentes à empresa Citrusul Importação e Exportação Ltda do município e sua relação com os quatro produtores de citros a ela vinculados.

Segundo Yin (2005) as entrevistas são umas das mais importantes fontes de informações para um estudo de caso e se destaca como técnica de coleta de dados deste trabalho. Bem como, de acordo com Lazzarini (1997), o estudo de caso é aplicável quando se deseja obter generalizações analíticas e não estatísticas, que possam contribuir para certo referencial teórico. A pesquisa por meio de estudos de caso tem sido enquadrada no grupo de métodos denominados qualitativos, que é caracterizado por um maior foco na compreensão dos fatos do que propriamente na sua mensuração. Esse método foi adotado por permitir um recorte temporal necessário para a análise e por permitir uma análise em profundidade do objeto de pesquisa. Entretanto, as principais limitações de tais estudos de caso são a subjetividade de análise e a impossibilidade de generalizações das conclusões (YIN, 1989).

http://cascavel.ufsm.br/revistas/ojs-2.2.2/index.php/reget 


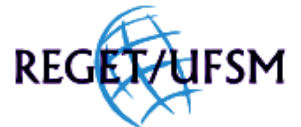

ALMEIDA et all , v(11), no 11, p. 2427-2436, JUN, 2013.

Rev. Elet. em Gestão, Educação e Tecnologia Ambiental (e-ISSN: 2236-1170)

O trabalho se concentrou em um roteiro referente aos seguintes eixos temáticos: produção de frutas, adoção de selos de certificação e acesso ao mercado externo. A coleta de evidências foi realizada com dados primários obtidos através de entrevistas semi-estruturas, sendo os depoimentos gravados e complementados com anotações feitas simultaneamente. Os resultados das entrevistas foram tabulados e analisados de forma qualitativa.

As fontes de dados secundárias utilizadas foram Anuário Brasileiro da Fruticultura (AGRIANUAL), Brazilian Fruit, Ministério do Desenvolvimento, Indústria e Comércio Exterior (MDIC), Instituto Brasileiro de Geografia e Estatística (IBGE) e IBD Certificações, além de livros e artigos publicados.

\section{RESULTADOS E DISCUSSÕES}

\section{A Citricultura na Fronteira Oeste do RS: o caso de Rosário do Sul}

O município de Rosário do Sul, situado na região da Fronteira Oeste do RS, dominada pela produção pecuária, vem se destacando entre os demais municípios por sua diversificação produtiva e por seu desenvolvimento no setor frutícola, principalmente pela produção de laranjas e tangerinas. Diferentemente de mais de $90 \%$ da produção brasileira de citros que é destinada à indústria, o município identificou como um diferencial de mercado apostar em frutas de mesa.

O zoneamento agroclimático da Embrapa aponta que as diferenças térmicas entre os períodos do dia e da noite, nesta região, favorecem a produção de frutas com mais sabor, coloração de casca e polpa, adequadas para atender as exigências impostas pelo mercado externo (OLIVEIRA et al., 2010).

A cultura começou a ser implantada no município a partir do ano de 2000 quando diversos municípios da região receberam recursos do governo federal, através do Programa de Fruticultura da Metade Sul. Os primeiros pomares começaram a produzir em 2003. Passados oito anos da primeira produção, o volume de colheita já aumentou em mais de 80 vezes, e as frutas rosarienses já estão até sendo consumidas no Canadá. Estima-se que até 2020 sejam colhidas pelo menos 15 mil toneladas de laranjas e tangerinas.

As principais variedades introduzidas foram: laranjeira Navelina, Lane Late, Navelate, Salustiana, Valência Late, Midknight, Delta Seedless e Cara Cara, de tangerineira Satsuma Okitsu, Clemenules e Marisol, e dos híbridos Nova e Ortanique. São frutas diferenciadas, algumas variedades sem sementes, a grande maioria in natura. Essas especialidades cultivadas necessitam de cuidados especiais, como uso de defensivos agrícolas, poda e limpeza freqüente das plantas. Os frutos são separados por tamanho, lavados e até encerados para a comercialização.

A comercialização da produção é feita através de uma entidade denominada Citrusul Importação e Exportação de Frutas Ltda, formada pela sociedade de seis produtores rurais. Esta 


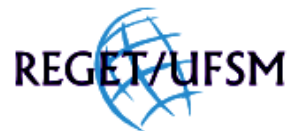

ALMEIDA et all , v(11), no 11, p. 2427-2436, JUN, 2013.

Rev. Elet. em Gestão, Educação e Tecnologia Ambiental (e-ISSN: 2236-1170)

empresa não possui fins lucrativos e foi criada para administrar todo o processo, desde a contratação de mão-de-obra para o manejo, classificação e comercialização, gerenciando no total 480 hectares de área plantada onde funcionam os quatro pomares do município.

O grupo é composto pelos pomares Arerunguá, Frutinter, Tono e Sombra do Caverá, onde no grupo de investidores/produtores rurais fazem parte um brasileiro, dois uruguaios, um canadense e dois espanhóis, além desta sociedade em solo rosariense, os sócios são grandes produtores de citros em seus países de origem. Os pomares compõem uma sociedade paritária, na medida em que todas as partes envolvidas são representadas em pé de igualdade. Cada viveiro possui uma área implantada correspondente a 120 hectares, com cerca de 60 mil árvores de laranjas e tangerinas em plena produtividade.

A Citrusul compra e comercializa as frutas produzidas nos quatro pomares, que totalizam mais de mil hectares com 240 mil árvores plantadas. Pretende ainda, a cada ano, aumentar a área com mais 20 mil novas mudas (40ha), para chegar à marca de 700 hectares. Emprega, pelo menos, 190 empregos diretos, sendo 30 na classificação e comercialização e 160 nos pomares. A relação dos pomares com a empresa central é de total dependência, pois esta foi criada para facilitar e diminuir custos, facilitando o controle dos insumos como estipulando o preço melhor para todos. Os lucros aferidos após cada fechamento do balanço são distribuídos aos quatro pomares conforme a sua participação.

No ano de 2011 a empresa produziu um total de 2.000 toneladas de frutas, onde parte desta fruta produzida foi comercializada em feiras e nas principais redes varejistas e de supermercados do país, como Carrefour e Wall Mart, e regionais, como Peruzzo e UnidaSul; outra parte foi destinada ao mercado externo, enviando, mais especificamente, um total de 200 toneladas de frutas (tangerinas) para o Canadá. Apesar de o mercado externo pagar mais, o custo para exportar ainda é maior por causa das exigências.

A empresa ainda não possui registro de certificação, no entanto, adota, desde sua fundação, diversos critérios e exigências de fundamental importância para o comércio, tanto no mercado interno quanto no mercado externo, sendo este ainda incipiente.

Atualmente, as certificações relacionadas no âmbito de gestão ambiental e social tornaram-se requisitos mínimos indispensáveis para que empresas possam exportar produtos agrícolas à determinados países. A certificação pode envolver o atendimento a critérios específicos, relacionados ao sistema de controle e monitoramento de processos (normas ISO), rastreabilidade, tipos de matéria-prima, insumos utilizados e métodos de processamento aplicados (produção integrada, produção orgânica), adoção de sistemas produtivos de baixo impacto no ambiente e inocuidade dos produtos, entre outros (ACOSTA, 2011).

Segundo o mesmo autor, a certificação socioambiental visa suprir as demandas dos consumidores por produtos ambientalmente corretos, garantindo que esses produtos cumpram com padrões que a certificação valida. Assim, algumas certificações socioambientais tornaram-se requisitos mínimos indispensáveis, para que as empresas possam vender seus produtos em mercados específicos. Esse é o caso de produtos agrícolas para exportação, cujas exigências são 


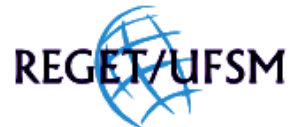

ALMEIDA et all , v(11), no 11, p. 2427-2436, JUN, 2013.

Rev. Elet. em Gestão, Educação e Tecnologia Ambiental (e-ISSN: 2236-1170)

impostas pelos países importadores, os quais estabelecem critérios que devem ser cumpridos. Para que as empresas demonstrem que seus produtos têm tais características, precisam de certificações, que avaliem esses critérios. Isso se deve ao fato de que quase todos os produtos agrícolas têm características relevantes, que não podem ser reconhecidas pelo consumidor, mesmo depois de um consumo repetitivo (COMPÉS, 2002).

Existem diversos selos de certificação socioambientais exigidos para a entrada de produtos pelo mercado internacional, principalmente in natura, dentre os quais se destacam a Certificação Orgânica e o GlobalGap. As barreiras técnicas de importação são diversas, porém, os selos socioambientais mencionados acima são considerados relevantes não somente para a colocação do produto brasileiro no exterior, mas também por seu apelo social e ambiental, portanto, serão abordados com maiores detalhes no presente trabalho.

Segundo Portilho \& Castañeda (2011), o rótulo de "orgânico" aplica-se aos produtos produzidos de acordo com normas de controle, desde a produção até a manipulação, processamento e comercialização. Podem ser classificados como "bens de crença", pois apresentam atributos de qualidade altamente específicos, não identificáveis mediante simples observação, necessitando de algum sistema de confiança que dê credibilidade ao produto. Nesse sentido, considera-se que os consumidores não possuem acesso perfeito à informação, utilizando critérios de experiência e de crença para escolher produtos deste tipo.

O registro orgânico nada mais é do que um conjunto de regras e de procedimentos adotados por uma entidade certificadora e auditora, que assegura por escrito que determinado produto, processo ou serviço obedece às normas e às práticas da produção orgânica. A certificação de produtos orgânicos é geralmente apresentada sob a forma de um selo afixado ou impresso no rótulo ou na embalagem do produto, tais como o GlobalGAP e a Produção Integrada de Frutas (PIF) (OLIVEIRA et al., 2010).

Para a Citrusul, a preocupação com a segurança do alimento tem se destacado como principal exigência a ser atendida para o comércio com seus clientes. Cadeias mais organizadas de supermercados exigem a adoção de procedimentos que estejam de acordo com certificações reconhecidas internacionalmente, em muitos casos, funcionando como barreiras e reguladoras dos volumes. Essas exigências referem-se a certificações, programas de qualidade e uma seleção apurada dos frutos. Destacam-se a observação aos limites máximos de resíduos permitidos, a sanidade e a higiene do processo produtivo e de embalamento, a rastreabilidade da fruta, etc.

Dessa forma, por se preocupar com a segurança alimentar e com a redução de riscos ambientais para o homem, a empresa adota regras visando uma produção econômica de frutas de alta qualidade, priorizando o uso de métodos ecologicamente seguros que minimizem as aplicações de agrotóxicos, evitando os efeitos secundários negativos desses produtos, o que promove a preservação do meio-ambiente e da saúde humana, através do uso de padrões adotados pelas certificações de Boas Práticas Agrícolas como, por exemplo, a GlobalGap e Produção Integrada de Frutas (PIF). 


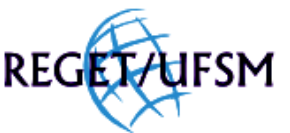

ALMEIDA et all , v(11), no 11, p. 2427-2436, JUN, 2013.

Rev. Elet. em Gestão, Educação e Tecnologia Ambiental (e-ISSN: 2236-1170)

Por meio dos critérios exigidos pela GlobalGap e pela Produção Integrada de Frutas (PIF) sistema de produção criado pelo Ministério da Agricultura, Pecuária e Abastecimento (MAPA) brasileiro - a Citrusul tem como objetivo ampliar sua participação no mercado externo. Além do Canadá, espera-se que em 2012 já se consiga atender a mercados no Oriente Médio e na Rússia, pois são consumidores que não determinam a necessidade de se possuir um selo registrado.

No Brasil, tanto os sistemas de confiança e credibilidade dos produtos orgânicos como suas formas de regulação vêm passando por um conjunto de alterações dos valores ligados a convenções sociais, em especial a confiança pessoal baseada nas interações face a face, para valores ligados à lógica industrial, como a padronização, a certificação e a auditoria, constituindo um comércio formalmente regularizado de commodities (PORTILHO \& CASTAÑEDA, 2011).

O desenvolvimento do mercado de orgânicos está diretamente relacionado à confiança dos consumidores quanto à autenticidade dos produtos, a qual somente pode ser assegurada por meio de programas eficientes de certificação. Além disso, a certificação é importante para a manutenção de padrões éticos do movimento orgânico, devendo estar desvinculada de interesses econômicos.

A certificação garante a procedência e a qualidade orgânica de um alimento natural ou processado. O agricultor ganha um diferencial de mercado, ao oferecer produtos de melhor qualidade e mais valorizados, estabelecendo uma relação de confiança com o consumidor. $\mathrm{Na}$ certificação orgânica, produtores e processadores são inspecionados e orientados segundo as normas de produção orgânica. O consumidor tem a garantia de um alimento sem contaminação química, cuja produção respeita o meio ambiente e o trabalhador (IBD, 2012).

Os selos de produtos orgânicos exigem uma série de cuidados, tais como: a desintoxicação do solo, o não uso de adubos químicos e agrotóxicos, a recomposição de matas ciliares, a preservação de espécies nativas e de mananciais, o respeito às normas sociais baseadas nos acordos internacionais do trabalho e o envolvimento do produtor com projetos sociais e com a preservação do meio ambiente (IBD, 2012). Assim, uma vez credenciada e acreditada, a propriedade pode gerar vários produtos certificados, que recebem o selo de qualidade, desde que obedecidos os requisitos de qualidade, rastreabilidade, sustentabilidade e padrão de vida dos trabalhadores.

Conforme estudo elaborado por Dörr (2009), o aumento da oferta de produtos orgânicos no mercado internacional, sobretudo o europeu, tem acarretado uma preocupação crescente dos governos em regulamentar os critérios para a comercialização de tais produtos. No Brasil os consumidores estão ainda muito centrados na variável preço e não no tipo de produto. Até mesmo pela dificuldade e desconhecimento do consumidor em identificar a procedência desse produto. Dessa forma, a maioria da população brasileira ainda não desenvolveu uma consciência da importância do consumo de alimentos saudáveis.

A União Européia não importa frutas de regiões que possuem o cancro cítrico, uma doença causada por uma bactéria altamente contagiosa que provoca lesões nas folhas, frutos e ramos, o que leva a queda dos locais acometidos e, consequentemente, da produção. No entanto, 


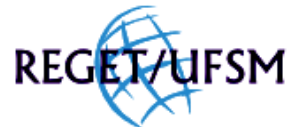

ALMEIDA et all , v(11), no 11, p. 2427-2436, JUN, 2013.

Rev. Elet. em Gestão, Educação e Tecnologia Ambiental (e-ISSN: 2236-1170)

essa bactéria é encontrada em todo o sul do Brasil galpões de embalamento e processamento póscolheita é de fácil disseminação e um de seus vetores é o homem. A única medida de controle, até hoje, reconhecida mundialmente como eficiente é a realização do manejo, através do método de inspeção constante e eliminação de plantas contaminadas e daquelas consideradas suspeitas dentro de um determinado raio.

Acredita-se que adoção de selos de certificação traria à empresa a oportunidade de acesso a mercados mais nobres e exigentes, uma vez que a empresa já trabalha para ter frutas de excelente qualidade. No entanto, devido ao volume de sua produção atual, acredita-se que os altos custos para seu registro não trazem retorno financeiro necessário para tal investimento.

\section{CONCLUSÕES}

A fruticultura é hoje um dos mais importantes segmentos do agronegócio brasileiro, destacando-se como uma importante alternativa para a geração de renda, para a alocação da mão-de-obra e para o aumento das exportações brasileiras de produtos agrícolas. Trata-se, portanto, de um segmento estratégico dentro da perspectiva de desenvolvimento sócioeconômico do país.

A demanda por alimentos frescos e de qualidade, que apresentem transparência nos processos de produção e ofereçam segurança para o consumo, tem aumentado em todo o mundo, mas especialmente em países desenvolvidos como os da Europa e Estados Unidos. Somado a isso, importantes canais de distribuição de produtos frescos, como as grandes redes de supermercados, repassam as exigências dos consumidores aos seus fornecedores, exigindo atributos de qualidade e segurança das frutas.

A internacionalização da fruticultura traz benefícios não só ao produtor que pode aumentar sua renda, mas também promove o desenvolvimento regional e nacional. Além disso, a fruticultura valoriza a terra de pequenos e médios agricultores, contribuindo diretamente para reduzir o êxodo rural e aumentando a qualidade de vida no interior do estado.

Para os produtores, a legislação brasileira ainda é o principal obstáculo ao acesso ao mercado europeu, pois tais leis não incluem o manejo como forma de tratamento da bactéria, uma vez que esta não permite sua erradicação devido às condições climáticas e de solo da região. Esse cuidado com o manejo dos pomares já é realizado em todo o solo rosariense, embora tenha o agravante da utilização de agrotóxicos como forma de proteger as lavouras de frutas e, portanto, os investimentos realizados.

Diante deste cenário, as certificações socioambientais tornaram-se requisitos indis pensáveis para que as empresas possam vender seus produtos em mercados específicos, pois através delas se atesta que determinado produto, processo ou serviço está em conformidade com os requisitos exigidos. 


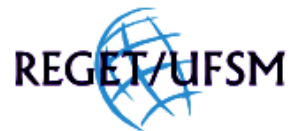

ALMEIDA et all , v(11), no 11, p. 2427-2436, JUN, 2013.

Rev. Elet. em Gestão, Educação e Tecnologia Ambiental (e-ISSN: 2236-1170)

Dessa forma, esta pesquisa objetivou fazer uma revisão bibliográfica para apresentar os benefícios que serão adquiridos pela adoção de certificações socioambientais para a fruticultura no município de Rosário do Sul, RS, para a preservação do meio-ambiente e para o desenvolvimento sócio-econômico da região.

Através da certificação, estes produtores poderão incentivar o aumento de suas exportações, trazendo mais divisas para o município, desenvolvendo a região de forma sustentável e criando novas oportunidades de negócios para os fruticultores. Além de ajudar na construção de uma imagem positiva do produto brasileiro no exterior.

Contudo, o alto custo para a adoção de programas de certificação socioambiental constatado pela empresa Citrusul destaca-se como a principal barreira ao acesso à certificação, tendo em vista a possibilidade de que o registro não trará, em curto prazo, retorno financeiro necessário para o volume atual da produção.

\section{REFERÊNCIAS BIBLIOGRÁFICAS}

ACOSTA, B.; PADULA, A. D.; REVILLON, J. P. P. Certificação e inovação em empresas de cultivo de rosas do Equador. Revista Organizações Rurais \& Agroindustriais, Lavras, v. 13, n.2, p. 176-185, 2011.

AGRIANUAL 2009: Anuário brasileiro da fruticultura 2009. 14. ed. São Paulo: FNP Consultoria e Comércio, 2009.502 p.

BRAZILIAN FRUIT. Promoção das Exportações de Frutas Brasileiras e Derivados. Fruticultura, 2012. Disponível em: < http://www.brazilianfruit.org/>. Acesso em: 05 jan 2012.

CARVALHO, J. M.; MIRANDA, D. L. As exportações brasileiras de frutas: um panorama atual. SOBER, palestra, 2009. Disponível em: <http://www.sober.org.br/palestra/13/1300.pdf>. Acesso em: 10 fev. 2012.

CERVO, A. L.; BERVIAN, P. A. Metodologia Científica. 4. ed. São Paulo : Makron Books, 1996.

COMPÉS, R. Atributos de confianza, normas y certificación: comparación de estándares para hortalizas. Economía Agraria y Recursos Naturales, Madri, v. 2, n. 1, p. 115-130, 2002.

DÖRR, A. C. Economic Analysis of Certification in the Brazilian Fruit Chain. Göttingen: Cuvillier Verlag Göttingen, 2009 p. 224.

EUREPGAP. Regulamento geral de frutas e legumes. [S.I.], 2004. 64 p.

IBD CERTIFICAÇÕES. Certificação Geral. Disponível em: <http://www.ibd.com.br/>. Acesso em: 20 fev. 2012.

INSTITUTO BRASILEIRO DE GEOGRAFIA E ESTATÍSTICA. Sistema IBGE de recuperação automática: SIDRA 2012. Disponível em: <http://www.ibge.gov.br/>. Acesso em: 20 jan. 2012.

LAKATOS, E. M.; MARCONI, M. de A. Metodologia Científica. 3. ed. São Paulo: Atlas, 2000.

LAZZARINI, S. G. Estudo de caso para fins de pesquisa: aplicabilidade e aplicações do método. In: 
REGETAUFSM ALMEIDA et all , v(11), no 11, p. 2427-2436, JUN, 2013.

Rev. Elet. em Gestão, Educação e Tecnologia Ambiental (e-ISSN: 2236-1170)

FARINA, M. M. Q. (Coord.). Estudo de caso em agrobusiness. São Paulo: Pioneira, 1997, p. 9-23.

MDIC (2012). MINISTÉRIO DO DESENVOLVIMENTO, INDÚSTRIA E COMÉRCIO EXTERIOR. Disponível em: < http://www.mdic.gov.br/>. Acesso em: 10 jan. 2012.

OLIVEIRA, R. P.; SCIVITTARO, W. B.; SCHRODER, E. C.; ESSWEIN, F. J. Produção Orgânica de Citros no Rio Grande do Sul. Pelotas, RS: Embrapa Clima Temperado, 2010.

PORTILHO, F.; CASTAÑEDA, M. Certificação e confiança face a face em feiras de produtos orgânicos. Revista de Economia Agrícola, São Paulo, v. 58, n. 1, p. 11-21, 2011.

YIN, R. K. Estudo de caso: planejamento e métodos. 3. ed. Porto Alegre: Bookman, 2005. p. 16.

YIN, R. K. Case study research, design and methods. Newbury Park: Sage, 1989. 165 p. 